\title{
TTR
}

Traduction, terminologie, re?daction

\section{Translation and Comparative Literature: The Search for the Center}

\section{André Lefevere}

Volume 4, numéro 1, 1st semester 1991

Languages and Cultures in Translation Theories

URI : https://id.erudit.org/iderudit/037086ar

DOI : https://doi.org/10.7202/037086ar

Aller au sommaire du numéro

Éditeur(s)

Association canadienne de traductologie

ISSN

0835-8443 (imprimé)

1708-2188 (numérique)

Découvrir la revue

Citer cet article

Lefevere, A. (1991). Translation and Comparative Literature: The Search for the Center. TTR, 4(1), 129-144. https://doi.org/10.7202/037086ar d'utilisation que vous pouvez consulter en ligne.

https://apropos.erudit.org/fr/usagers/politique-dutilisation/ 


\title{
Translation and Comparative Literature: The Search for the Center
}

\author{
André Lefevere
}

"Translation" is by now a word that needs translating. It can mean so many things to so many people that it is best for anybody writing on the subject to state at the outset what kind of translation they are concerned with. There is the production of translations, literary and technical, there is the teaching of that production, literary and technical, and there is the thinking about both the production, literary and technical, and the teaching thereof. The present text falls under the third category, that of thinking about translation and, more particularly, about the translation of literature.

It is my contention that those of us who think about the translation of literature have reached a turning point. It has been more or less generally accepted that the "workshop approach," designed to teach students how to translate, has its place, but that it does little to improve the status of translation within the profession that deals with the study of literature. Far too often, translation workshops in the United States turn out to be creative writing workshops in disguise, and the products emanating from them mirror with amazing fidelity the style fashionable in American literature at the time the workshop was offered. In fact, historians of literature interested in ascertaining the dominant poetics of a given decade in American literature would be well advised to study the translations produced by workshops; they would provide them with an unfailing barometer of literary fashions.

The workshop approach is limited in other ways. Workshops are too often populated by students who, while believing themselves 
to share Rilke's (say) sensitivity and world-view (sometimes even to the point of claiming some degree of reincarnation), tend to "have trouble with those little words in German." The "little words" are, of course, the prepositions that rule the use of cases and are an absolute sine qua non for the correct understanding (let alone interpretation) of any German text. In other words, students' knowledge of foreign languages is often inadequate, and the translation workshop, besides doubling as a creative writing workshop, also finds itself doubling as a language class. I shall show later that this puts it squarely in a venerable tradition in the history of language (and literature) teaching in Europe and the Americas, but I also hope to argue that it is necessary to go beyond this tradition now. Students' inadequate knowledge of foreign languages, combined with the image of the translation workshop as a place rejected would-be creative writers retreat to, obviously does not help to endear that workshop to the institutions of academe. Translation workshops are tolerated the way slightly eccentric maiden aunts are. The latter rate a yearly Christmas card, the former are mentioned towards the end of any course catalogue or dean's address. It would seem, therefore, that the workshop approach is not one that will ensure increased professional and institutional respectability for the study of translation.

I have used the phrase "study of translation" advisedly, and I would use it interchangeably with the term "translation studies." Both terms imply that the quest for professional and institutional respectability mentioned above is not likely to be crowned with any degree of success as long as those interested in the field remain the captives of the workshop approach.

Translations need to be made, of course, and people need to gain experience in how translations can be made. That is the role and place of the workshop or, even better, the one-to-one translation project for which teacher and student sit down together with a specific text and try to translate it. It is obvious that workshops will not be able to generate universally valid "rules" for the production of translation, not are they supposed to. The workshop approach should serve to alert the student to the existence of certain problems in the translation of literature and to point out the existence of certain strategies that can be used to deal with those problems. Older and/or different translations of one and the same text can be very illuminating in this respect.

Translations need to be made, but translations also need to be studied. The study of translation, though, should in no way be 
equated with the workshop-confined process of "learning to translate," which is still dominant in the American academy. Rather, the study of translation touches on the very core of literary theory, it comes much closer to the center than the workshop approach can ever hope to. The only problem is: the center of what? Should "translation studies" constitute itself as a new, independent discipline? I believe it should not, for various reasons.

The first reason is the one I would like to call "overreaction to marginality." Translation scholars who have seen their efforts to move beyond the workshop bear at least some fruit in recent years should beware of the temptation beguiling all those at work in marginalized (unjustly so, from their point of view, of course) fields of inquiry. That temptation consists on the one hand of the making of largely unsupported boasts for the obvious importance of the field, nurtured to no small extent by a not always decorously muted desire for some kind of revenge, and on the other of generating abundant, and for the most part superfluous "fieldspeak," the kind of jargon that amounts to semantic terrorism and is conducive mainly to increasing the "splendid marginalization" of the field, any field, in question. Potential practitioners tend to be repelled, rather than attracted by "fieldspeak," which proliferates in any marginalized field only because those working in that field feel they have to use this ploy to claim the respectability denied to them in the "real" world of academe, to use a mild oxymoron. It is an old trick, and one that has been used by those in power (in the center) to pacify those without power (in the periphery). Think of the patriarchal and patronizing missionary telling his black employee in colonial Africa that he will make it to "chief senior messenger boy, or CSMB" in no more than ten years from now. The trick is not new, but it is now used in a new, and disturbing way; far from being imposed by the dominant, it is willingly and wittingly used by the dominated, who have interiorized their marginality to such an extent that they cannot think of any other way to go beyond it.

The second reason is that "independent translation studies" run the risk of regressing to the workshop. After all, if you stay with texts and their translations only, without paying much attention to the part translations play in the evolution of a literature, or in the way one literature influences another, there does not appear to be much of another direction to go in. Moreover, "independent translation studies" are most unlikely to make the distinction between literary and non-literary, or technical translation. This is not a bad thing in itself, especially if one reflects on various text types, such as 
philosophical and religious, even historical texts that appear to be predestined to the status of borderline cases, no matter what classification is adopted. Lack of any classification, however, tends to confuse the issue, and may awaken expectations that cannot always be fulfilled.

The third reason is an old one, but one that has been invested with a new urgency by the way in which "world literature" is being taught in practice in many, if not all, American (and, to a lesser extent, European) schools and universities. Not only are the "great books" belonging to the "canon" of "world literature" increasingly taught in translation; they are also increasingly taught in excerpts, usually collected in mammoth anthologies which not infrequently turn out to be one of the mainstays of many a publishing corporation. It has always been known, or at least suspected, if rarely acted upon, that statements like "writer X belonging to literature A was obviously influenced by writer $Y$ belonging to literature $B$," need to be qualified by reference to the actual form in which writer $X$ was exposed to the works of writer Y. There is hardly a textbook on English literature, or an introduction to the relevant segment in one of the current anthologies, that will neglect to point out that Byron, for instance, was "heavily influenced" by Goethe's Faust. What is usually not said is that Byron could not read German, and that no complete translation of Faust in any of the languages he could read appeared until some years after his death. The Faust he knew was the one he could read in Madame de Staël's book De l'Allemagne: a synopsis of the play supplemented by translations of some of the major scenes. Similarly, Pushkin, always said to have been "heavily influenced" by Byron, was unable to read Byron in English, or in Russian. He used a French translation.

Needless to say, the shape of the work that exerts the influence can define the nature of that influence to no small extent. This rather salient fact has often been overlooked in histories of literature and studies of influence, but fortunately with consequences limited to those who study and teach literature. The large-scale packaging, cutting, and pasting of literature that is going on at present, for pedagogical purposes, of course, is another matter altogether. People who are not likely ever to pursue any scholarly study of literature in later life are exposed to these "packaged versions" in high schools and during the required courses they have to take at many universities. If they are not going to study literature on a more advanced level - and there is no categorical imperative that says they should - they will accept the package as the product, since the 
package is all they are ever likely to be exposed to. It should be obvious that this development in high school and university teaching of literature concentrates an enormous amount of power in the hands of the "packagers." It should be equally obvious that the existence of this power is rarely, if ever suspected. Is the packaging not done, after all, by bona fide educators whose only aim is to introduce their students to something like "the best of what was ever thought and express'd?"

It is not my intention to call the bona fide of the packagers into question. I merely want to state, clearly and unequivocally, that their existence is a fact of literary pedagogy, as is their power. They project images of a literature, a writer, a work, for students to assimilate and reproduce, and it is most unlikely that the majority of the students exposed to the image will ever discover the reality behind it. Ask any busy executive if she or he has ever read Marlowe. The answer is likely to be a resounding yes, since to answer no would be to confess to literary illiteracy, which is still not one of the executive's assets. Dig a little deeper and your executive will tell you he or she most likely read Faustus's last speech in Dr. Faustus in some anthology, and that she or he vaguely remembers that Marlowe was knifed to death in some tavern.

What used to affect the study of the evolution of a literature, or the influence of one literature on another, and did not necessarily go much beyond the boundaries of literary studies, now profoundly affects the very way in which literature is taught. The power wielded by this packaging therefore needs to be analyzed, and this can be done most productively, I submit, if the tools developed in recent years by the variant of "translation studies" described above are brought to bear on the task. Needless to say, this also implies that the variant of translation studies referred to cannot be "independent." More: it need not be independent. The very claim to independence risks robbing of much of its potential relevance, a relevance that goes beyond the boundaries of literary studies. It need not be independent because it finds itself close to the center of both literary theory and comparative literature, even though that is not always immediately clear to both, or either, of its - usually still somewhat reluctant hosts. There are historical reasons for this reluctance, and these must now be analyzed.

Since the inception of Comparative Literature as an academic discipline, both the production of translations and the study of those productions have been relegated to a position close to the sidelines of 
its field of study and research as that field has developed over the decades. In what precedes I have adduced institutional reasons that will lead to change in this state of affairs. As is often the case, these institutional reasons are linked to developments in more abstract thinking about the field itself. This thinking has been, and is being subjected to rather radical review in the wake of recent developments in literary theory. This is obviously not the place to expatiate at some length on deconstruction, or postmodernism, or both. It is sufficient for my purposes to point out that either, or both, have contributed to the more general acceptance in the humanities of what has been common knowledge in the sciences for at least five decades: that what we call "reality" is a construct. Just like literature, "reality" is increasingly packaged for us, in the textbooks we use in schools and universities, and especially, on a daily, even hourly basis, by the media. When we refer to reality we mean the current packaging that has held up best: a post-Copernican, say, as opposed to a Ptolemaic universe. When many of the students whose training in literature ends after they have taken their last required "world literature" course in their first year at university refer to "Goethe," they most probably have in mind five or six poems in translation, supplemented by Faust's opening monologue in the play of that name. These are facts, and we must live with them.

By the same token various subsets of what is currently packaged for us as reality, such as "society," and "literature" do most definitely not represent eternal and immutable givens (even though the publishers of the various competing anthologies do their best to persuade prospective readers that they do, if only to boost such tangible economic factors as sales). Rather they are constructs, packagings that are the product of certain forces interacting in a certain time and in a certain place. Like all images, constructs, packagings, they reflect both "fact" and "hypothesis." They are a mixture of observation, or the gathering of facts, and theory, or the framing of a narrative that succeeds in making the most sense out of the most facts - often in the most economical way. In the field of literature they are a mixture of, on the one hand, words on the page, historical data, and information about the life of the writer, if available and, on the other hand, a framework that claims to endow these "facts" with the "meaning" that makes most sense and is most relevant - from the packagers' point of view. Every packaging reflects a point of view, is undertaken with a certain goal in mind, whether that goal is some form of mild, surreptitious, or harsh ideological indoctrination, or whether it is mainly inspired by the ideology of profit. It is my contention that translation, as one form of packaging 
among others, is one of the loci where the very process of packaging can be made to reveal itself, not only within the study of literature, but also within the wider context of the historical development and interaction of societies as such. Translations and other forms of rewriting, such as the putting together of anthologies, the writing of literary criticism, the production of editions, and the writing of literary history show us the packagers at work. They only do so, of course, if we are convinced that this packaging is, indeed, going on. If we are, the study of these types of rewriting becomes an amazingly simple, yet efficient instrument for the study of packaging, of manipulation in many forms and circumstances. If we are not convinced that packaging is indeed going on, we shall dismiss the same instrument as either superfluous or potentially subversive.

If we accept that packaging is indeed going on, we shall have little trouble understanding that it has always revealed itself in translation, but that it has by no means always been allowed to reveal itself - precisely by those who do not believe packaging is going on. Since revealing the constructedness of things implies revealing the ways and means to construct possible alternatives to the dominant construction, that kind of revelation was and is not always looked upon in a favorable light. Hence the emphasis, over a long concatenation of centuries, on the production of "faithful," "good," or "right" translations. Once it becomes intellectually and institutionally acceptable to reveal constructedness, it stands to reason that translation or, in more general terms, translation studies will also be allowed to do so. As a result, translation studies is bound to become more centrally relevant to both literary theory and comparative literature in the current intellectual constellation.

To analyze the constructedness of things literary, translation studies work with a number of variables, namely (1) the institutionalized way in which both translation and literature are taught, (2) the audience translations are made for, (3) the literary production in its interaction with the literary theory-cum-criticism that accompanies it, and (4) the self-image of a culture, often underwritten by a text (the Bible, for instance) considered "central" to that culture by most, if not all of its members.

This kind of analysis has been made possible by a "turn to history," or even anthropology, taken recently in translation studies, and not so recently in other disciplines belonging to the humanities. By investigating other worlds, distant in either space or time, the historical/anthropological perspective emphasizes the relativity, reveals 
the packaging, not just of the worlds studied, but also of the world to which students of those other worlds belong. It therefore becomes possible to speak of translation in terms other than right or wrong, and to free translation studies from the limitations imposed by views of the world, and literature, that have traditionally considered themselves absolute, and therefore also superior to the worlds they studied, and whose relativity they could acknowledge in a patronizing, and therefore ultimately non-threatening manner.

Traditionally in the West, at least since the final century of the Roman Republic, translation has been taught in an institutionalized manner in the classroom. Translations produced in this "space" were primarily designed to function as a "proficiency test" for the students' knowledge first of Greek, then of Latin and Greek, and they were usually produced for an audience of one, which was invested with absolute authority conferred upon him both by the institution he belonged to and the body of canonized texts he represented. The audience also did not need the translation; if the teacher wanted to read Homer or Tacitus he could obviously read them in the original, without having to rely on any translations whatsoever. Rather, the original was seen as the yardstick against which all translations needed to be measured. Two consequences of this way of teaching translation are still with us, even though translation itself is no longer taught this way here and now. The first consequence is the zeal worthy of much better causes with which much thinking about translation has insisted and, to some extent, will still insist on the right/wrong, faithful/free opposition, to the exclusion of any other possible consideration of the phenomenon. Over the centuries, this zeal resulted in a strong emphasis on rules and rule-giving, whereby the activity of formulating the rules was seen as all-important and the sense of their own non-relativity blissfully shielded rule-givers from the potentially embarrassing questions that might have been raised by the fact that the rules they, their predecessors, and their successors promulgated over the centuries were very obviously subject to - sometimes radical - change. More recently, the emphasis on rule- giving has been supplemented by the increasing attention paid to the problem of translatability that has become evident in much thinking on translation that has traditionally taken its bearings first from grammar, then from philology, and finally from linguistics.

The second consequence of the traditional way of teaching translation in the West is the enormous discrepancy in status between the original and the translation, reinforced by the self-image of the receiving culture: the Romans were deeply convinced of the superior- 
ity of Greek, and students introduced to the Greek and Roman classics in the European Renaissance received that introduction from a teacher deeply convinced of the superiority of source over target texts and cultures. This discrepancy in status also illustrates the difference between the non-relativity ascribed to the translator's own world, and the relativity he or she ascribed as a matter of course to other worlds: Victorian translators did things to the Arabic, Persian, and Indian classics they would never have dreamt of inflicting on the classics of Greek and Latin literature.

Style is the element that links the first and the second spaces to be discussed. The student translating the Greek and Roman classics in class was, primarily, supposed to show that he understood the text. The improvement of his personal style as a consequence of his "emulation" of the original was seen as a desirable side-effect. In the space in which literature was produced, emulation was seen as the next step; once you knew what the text said, you could then improve your style by measuring yourself against the author of that text. It is important to note, though, that since Cicero, and then again since the early Renaissance, this improvement was by no means thought of as limited to personal style. Rather, the translator was also expected to improve his or, in rare cases, her own national language. No language could claim full membership in the assembly of civilized tongues as long as it had not proved that Homer and Virgil could be translated into it with ease and elegance. As long as this had not been proved, a language and its world would be seen as hovering somewhere between the relative and the non-relative. Only when it could reproduce the absolute standards of the Greek and Roman classics would it also inherit their mantle of absolute respectability.

It is interesting to note, in this respect, that this process was, and is, by no means limited to the European Renaissance. During the Czech revival in the nineteenth century, for instance, many Czech men of letters insisted on translating the German classics into Czech, even though there was, strictly speaking, neither an audience nor a need for the fruits of their endeavor, since all literate Czechs were likely to be able to read German as well as they could read Czech, while many of them were likely to be able to write German better than they could read Czech. Similarly, Julius Nyerere, the former president of Tanzania, did not translate Shakespeare into Swahili because Shakespeare was inaccessible to most of his literate fellow- countrymen who had been educated under the British colonial system, and many of whom had pursued their higher education in Britain, the United States, or Canada. Rather, he wanted to show them that 
Swahili could also do what English could, and that it had therefore earned its place alongside the language of the former colonizers and the literature produced in that language.

Once the so-called vernacular languages of Europe had been admitted to the company of civilized cultures, however, the concept of emulation was not abandoned, but transformed. In the seventeenth century, writers writing in languages which had passed the test would think of themselves and the "ancients" as co-existing in a "timeless" space, in which they would all rival each other in the pursuit of excellence as codified by the rules given in the textbooks of, and treatises on poetics that were published with great regularity. With the same regularity these poetics devoted one or several chapters to translation, which was self-evidently thought of as an integral part of the study and production of literature. Translation then was much closer to the center than translation is now, though perhaps not as close as it will be again.

In the context of this timeless rivalry within a well-defined space of excellence it was not rare for translators actually to correct their originals where they thought the authors of those originals had fallen short of excellence. Nor did it matter much, since they all wrote for a limited audience, consisting mainly of a number of replicas of the school-teacher they had studied with. That audience did not read translations to learn what the original had to say; if they wanted to do that they might as well read the original, and they did. Rather, they read translations to see what the author of the translation had done to the original, and commented accordingly.

They realized full well that the translator would have to do something to the original, for at least two reasons. One was the tension that invariably arose between the first and second spaces of translation as referred to here. While the school-teacher would emphasize faithfulness, the absolute, the translator operating in the literary space knew that he had to reconcile two poetics, one absolute and one relative. He or she found it impossible to observe total faithfulness to the original while producing rhymed verse in the translation. The second reason has, once again, to do with the self-image of the receiving culture. Not only did neo-classicism think it had earned the right to deal with the Greek and Roman classics on a footing of equality, but neo-classical translators would often assume that their own culture was superior to the more uncouth ways of Homer in many respects, and delete or rewrite accordingly. In this configuration translation becomes, perhaps for the first time, a way to 
influence the dominant poetics of a literature and a period, and even, in the early translations of Shakespeare into French and German, to introduce an alternative poetics.

Romanticism shattered both the timeless space referred to above and its monolithic excellence, replacing them with both historical distance and a number of rival concepts of excellence. Yet the teleological view of human history did not allow the Romantics to probe too deeply into the relativity of worlds, their views, and their literature. By challenging the current absolute they saw themselves as, paradoxically, having inherited the mantle of the absolute per se. Certain worlds, both in time (the Middle Ages) and space (India) could be seen to be relative, but the Classical World that no longer embodied excellence as such, but rather the idea of excellence, now implemented in the Romantic world view, was not. You do, after all, not saw off the branch you claim to be sitting on. Romanticism also replaced the concept of the writer as craftsman, which tended to place "authors" and "mere" translators on a footing of greater equality, with that of the author as genius, who achieved excellence of craftsmanship, to be sure, but maybe only as an afterthought. Romantic authors primarily spread what was later to be codified in Matthew Arnold's immortal phrase "sweetness and light."

They did so at a time when the audience had also undergone a profound transformation. For reasons that need not concern us here, many more people were reading, and many fewer of those were able to read Greek and Latin in the original. As a result, the critics who could, tended to become school-teachers more than ever, emphasizing "fidelity," the "right" rendering of the original, with the kind of zeal that had been reserved until then for the translation of Europe's central text: the Bible. Bible translators had always been potentially suspect in the eyes of the different dignitaries of different churches, because they had the power to subvert the central text on which churches based their authority. Translators of literature now became just as suspect, again for at least two reasons, the first, and most obvious, being that from the middle of the nineteenth century onwards literature increasingly began to play the role of a "secular scripture," whose central texts therefore had to be protected against impostors and handed down to future generations whole and pure. The second was that after the demise of the (neo-)classical concept of excellence the canon of (world) literature could not remain as restricted as before. To everybody's dismay, however, candidates for admission to the new canon could most easily be introduced only by the distrusted translators. 
Romanticism in literature, philosophy, and the arts, coincided with a third momentous development in European history: the whole-hearted expansion of European powers into non-European cultures, not just in parts of Africa and the Americas but also, particularly, in Asia. Faced with alternative worlds actually existing in space, rather than reconstructed in time, the self-image of the receiving culture came into play as never before. As stated above, the status of the Greek and Roman classics was not just maintained but enhanced; the new awareness of the Classical World as the source of the idea of excellence, combined with historical research designed to reconstruct, never to relativize it, militated against any further "corrections." Yet, as stated above, these same corrections were matter-of-factly administered to the classics of Asian literatures, if only to make them read more like the Greek and Roman classics. It is important to note, though, that these corrections are not only inspired by a feeling of superiority, but also by the desire to make these authors known, to introduce them to the emerging canon of world literature. Yet this introduction took place under objective conditions that favored the Western model of the evolution of literature and universalized it, projecting it - most inappropriately, of course, but projecting it nonetheless - on literatures produced elsewhere under different conditions. In other words: literature produced in the dominated worlds could enter the dominating world only after it had been rewritten in such a way as to fit in with the dominant poetics of the dominant world. The fact that the dominated worlds were seen as relative, and the dominating world as absolute, gave translators and scholars greater freedom in their treatment of texts produced in those dominated worlds.

Finally, Romanticism demoted translators: they became mere craftsmen, doing a decent job, no doubt, but sinking into insignificance next to "real" authors. Unfortunately for the status of translators today, and for the status of translation studies as a whole, this image of the translator became institutionalized when philology began to find its institutionalized expression in the administrative categories adopted by universities that are still with us today. The new national philology departments had to emphasize the reading of texts only in the original, not least because the much older and academically more respectable departments of classics had been doing so for centuries. Comparative literature departments had no option but to follow suit. "Real" scholars read their texts in the original, not in translation. 
The audience, it may be safely assumed, did not care all that much. The great majority of new readers would read for pleasure, intermingled with a modicum of edification, and if translations brought pleasure they were welcome. As a result, translators began to work for a double audience, producing "reliable" translations for the eyes of academic critics, and "profitable" translations for the eyes of the reviewers who were on the whole utterly ignorant of the language of the original and demanded only, in the well-known phrase, which also doubled as the highest praise they were able to bestow "that the translation read like an original."

The situation is changing again, and has been for a while, because we need to add a final "space": that of relativity, constructedness, the revelation of both the packaging and the reasons for packaging a literature, to be sure, but also a world in this current way, and not in any other - for the time being. This involves a rethinking of the role of "writing on literature," both literary criticism and literary history as we used to know them. The confident histories of literature are a thing of the past, and not too many among criticism's dwindling audience still read it with any hope of being offered a "definitive" interpretation of any text. Definitive interpretations, it would seem, have finally, and permanently been relegated to the institutionalized space reserved for the teaching of literature, where students first ascertain the teacher's critical/theoretical allegiance, and then proceed to store the relevant critical texts for reproduction in examinations set by that teacher. Students will switch from one critical "store" to another with the same ease with which physicists switch from the wave to the particle theory of light, and for the same reason: they want results. Outside of the institutionalized space of the literary classroom criticism is not expected primarily to elucidate "what oft was thought, but ne'er so well express'd," but rather to tell us why some thoughts were thought at a certain place and in a certain time, and why they were expressed in a certain manner.

We do not teach translation in many classrooms any more, but much of what we teach in classrooms, as well as the vast majority of texts perceived as literature outside of our classrooms, appears in some form of translation or, as I prefer to call it, rewriting. Non-professional readers of literature will increasingly be exposed to literature in its translation for comic strips, film and television. Students of literature are introduced to literature by means of anthologies, which offer extracts more often than complete texts, and which select certain authors and texts to the detriment of others. Students write about literature with the help of literary histories and 
works of criticism, which also constitute, or at least contain, rewritings of the original: the potted version of the plot, the analysis of symbols and metaphors, not to mention complexes and archetypes. Both inside the classroom and outside of it what we call "literature" in our day and age is an amalgam of all this, combined with the printed texts of the originals.

The original still exists, of course, but it is surrounded by countless rewritings, which are often as, if not more influential in assuring/ensuring its impact on society than the original is itself. It is doubtful, to say the least, that the proverbial executive will have actually ploughed through the whole of Moby Dick. Rather, she or he will have read extracts, seen the movie with Gregory Peck (or even the older version with John Barrymore, if he or she has access to certain cable channels), and maybe glanced at the comic strip version one of his or her children happens to be leafing through. It should also be pointed out that many originals themselves turn out to be rewritings, at least in terms of theme and plot. Hardly one of Brecht's (or Shakespeare's, for that matter) plots can be called "original" in the way hallowed by Romantic writing about literature.

This growing tendency to redefine originals contributes to changing the relative status of "the original" once again. It also invites us to tackle the study of literature from at least two additional directions: one would be the study of the image literature creates of a world, whether by means of original texts or rewritings; the other would be the study of the conditions under which this image is created, the conditions that determine which image will be acceptable to the receiving culture and which will not be. It is increasingly realized that these conditions have less to do with the aesthetic value of the text as such, and more with power and the struggle between various concepts of culture, or even between various concepts of poetics. The fate of many of the recently republished "feminist classics" provides us with an excellent example: the "intrinsic aesthetic value" of many of these "forgotten classics" was probably the same when they were published in the twenties and thirties, only to sink without a trace, as it is now, when they are being republished, and do not sink anymore, precisely because they are being "rewritten": attention is drawn to them in the criticism that appears in Sunday papers and magazines, they are analyzed in critical journals, and they are incorporated into histories of (women's) literature.

The meta-literary space sketched above will, inevitably, be increasingly filled by discussions on multiculturalism. The self-images 
of different cultures will have to be redefined in conjunction with each other, and there will be few reasons to keep excluding the literatures of many cultures we used to call "exotic" or "marginal" only yesterday, from exposure at least to the "mainstream," or canon once more in the process of being revised. This means more work for translators, whose status is also on the rise again with the corresponding gradual demise of the "author as genius" concept. It means academic work for translators, not work for the commercial market, and this in itself may lead to a revaluation of the work of academics who translate within the confines of academe. If the study of literature is indeed shifting from the sweetness and light individual readers can garner from individual texts to a more general study of the relationship between a literature and its surrounding culture, translators will, once again, have the incentive to provide texts for study and analysis.

But the real chance for translation studies lies elsewhere still; the interaction between cultures and the projection a given culture itself makes of its literary heritage for pedagogical purposes can nowhere be better studied or analyzed than in the laboratories in which rewritings (translations, literary histories, works of criticism, anthologies) are produced. The study of translations and other rewritings is likely to shed much more light on the process of canonization and its wider implications of cultural manipulation and domination than was considered admissible in the old literary space. But then, manipulation is a fact of not just literary life, and the (meta-literary) analysis of it therefore even risks endowing (comparative) literary studies - at last - with a certain relevance beyond the borders of their domain.

In fact, it might be argued that just as translation studies have been freed to assume a more central role within the wider context of (comparative) literary studies, literary studies themselves have been freed to assume the role of a laboratory in which all kinds of verbal and conceptual manipulations, packagings, and constructions, can be studied because literature no longer functions as a "secular scripture" in our day and age, if only for the very obvious reason that far fewer people read it now than a hundred years ago. Today's teenagers are far more likely to recognize themselves in the appropriate sitcom or soap than in Huckleberry Finn, and today's adults are just as likely to turn to celluloid, not paper, for their role models, if any.

Now that literature need no longer spread "sweetness and light," the study of literature may well be able to lift itself to a level 
of technical expertise that may contribute to making it more respectable within the institution of academe itself. Manipulation is all around us all the time, and many more of us are victimized by it than profit from it. The manipulation of such supposedly absolute values as truth and justice contributes much more to the conquest and legitimization of power than those values themselves. At a time when reality is packaged to perhaps the greatest extent in history, it might be worth taking a closer look at the process of packaging and its techniques. It is my contention that we could do worse than start with the study of literature, both written (or packaging a world in terms of world view and poetics) and rewritten (repackaged for different worlds and subjected to the impact of different poetics). 